Check for updates

Cite this: RSC Adv., 2019, 9, 30171

Received 18th July 2019

Accepted 9th September 2019

DOI: $10.1039 / c 9 r a 05558 d$

rsc.li/rsc-advances

\section{Stepwise engineering of Saccharomyces cerevisiae to produce $(+)$-valencene and its related sesquiterpenes $\uparrow$}

\author{
Xiaodan Ouyang, (D) ${ }^{a}$ Yaping Cha, (D) ${ }^{a}$ Wen Li, (D) ${ }^{a}$ Chaoyi Zhu, (D) a Muzi Zhu, (D) b \\ Shuang Li, (iD *a Min Zhuo, (D) a Shaobin Huang (D) ${ }^{c}$ and Jianjun Li (D) b
}

$(+)$-Valencene and (+)-nootkatone are high value-added sesquiterpenoids found in grapefruit. The synthesis of $(+)$-nootkatone by chemical oxidation from $(+)$-valencene cannot meet the increasing demand in natural aromatics markets. Development of a viable bioprocess using microorganisms is attractive. According to the yields of $\beta$-nootkatol and $(+)$-nootkatone by strains harboring different expression cassettes in the resting cell assay, premnaspirodiene oxygenase from Hyoscyamus muticus (HPO), cytochrome P450 reductase from Arabidopsis thaliana (AtCPR) and alcohol dehydrogenase (ADH1) from Saccharomyces cerevisiae were finally selected and overexpressed in CEN.PK2-1Ca, yielding $\beta$-nootkatol and (+)-nootkatone with 170.5 and $45.6 \mathrm{mg} \mathrm{L}^{-1}$ ethyl acetate, respectively. A combinational engineering strategy including promoter change, regulator ROX1 knockout, squalene pathway inhibition, and HHMG overexpression was performed to achieve de novo (+)-valencene production. Subsequent culture investigations found that galactose as the induced carbon source and a lower temperature $\left(25^{\circ} \mathrm{C}\right)$ were beneficial to target accumulation. Also, replacing the inducible promoters (GAL1) of HPO and AtCPR with constitutive promoters (HXT7 and CYC1) dramatically increased the $\beta$-nootkatol accumulation from 108.2 to $327.8 \mathrm{mg} \mathrm{L}^{-1}$ ethyl acetate in resting-cell experiments using $(+)$-valencene as a substrate. Finally, the total terpenoid titer of the engineered strain of PK2-25 using glucose as a carbon source was improved to $157.8 \mathrm{mg} \mathrm{L}^{-1}$ cell culture, which was 56 times the initial value. We present a new candidate for production of $(+)$-valencene and its related sesquiterpenoids with attraction for industry.

\section{Introduction}

Sesquiterpenes are a class of abundant natural products derived from the 15-carbon linear precursor, farnesyl pyrophosphate (FPP). (+)-Valencene is an important sesquiterpene that is an aroma ingredient in orange peel oil. Its odor characteristics include fresh citrus notes with sweet, orange and woody balsamic profiles. ( + )-Nootkatone is an oxidized product of $(+)$-valencene. It is the main contributor to the aroma component of grapefruit and citrus-derived odorants with relatively low perception threshold. ${ }^{1,2}$ Applications of these compounds include food and beverages, fragrances, personal care and

${ }^{a}$ School of Biology and Biological Engineering, South China University of Technology, Higher Education Mega Center, Guangzhou 510006, China.E-mail: shuangli@scut. edu.cn; Fax: +86203938 0601; Tel: +862039380601

${ }^{b}$ State Key Laboratory of Applied Microbiology Southern China, Guangdong Provincial Key Laboratory of Microbial Culture Collection and Application, Guangdong Institute of Microbiology, Guangzhou 510070, China

${ }^{c}$ School of Environment and Energy, South China University of Technology, Higher Education Mega Center, Guangzhou 510006, China

$\dagger$ Electronic supplementary information (ESI) available. See DOI: 10.1039/c9ra05558d home products. It is on the authorized flavor list with a $0.5 \mathrm{mg}$ $\mathrm{kg}^{-1}$ concentration level for food in the European Regulations by the European Food Safety Authority. ${ }^{3}(+)$-Nootkatone is reported to have several pharmacological properties, such as antioxidant, antiseptic and antiallergic activities, and is also an effective repellent against such various insects as mosquitoes, bed bugs, termites and ticks. ${ }^{4}$ Recently, (+)-nootkatone was considered as protective agent against air pollution-induced respiratory effects. ${ }^{5}$

Employing conventional extraction processes from natural sources, it takes 2.5 million kilograms of oranges to obtain a single kilogram of (+)-valencene. The trace amount of $(+)$-valencene and (+)-nootkatone in natural plants leads to high price of these fragrance compounds. ${ }^{6}$ The high cost, limited supply and inconsistent product quality have restricted their applications. Several chemical synthetic strategies have been developed via the Robison annulation, intramolecular Sakurai reaction, and Diels-Alder/Aldol tandem reaction, etc. ${ }^{7}$ However, the mentioned above generally provide racemic $( \pm)$-nootkatone. One-pot synthesis of $(+)$-nootkatone through singlet oxygenation of $(+)$-valencene has been realized with carcinogenic tert-butyl 
hydroperoxide in combination with $\mathrm{Co}(\mathrm{OAc})_{2}, \mathrm{Cu}(\mathrm{OAc})_{2}$ or $\mathrm{V}(\mathrm{OAc})_{2}$ catalysts. $^{7}$ The explosive, corrosive, and toxic heavy metal chemocatalyst requirements of the chemical approaches call for greener and more effective methods for $(+)$-valencene and (+)-nootkatone preparation. Previously, $(+)$-valencene extracted from Valencia orange was converted into (+)-nootkatone by biotransformation using Aspergillus, Rhodococcus, Chlorella, Mucor species Botryodiplodia theobromae 1368, Yarrowia lipolytica 2.2ab, and Phanerochaete chrysosporium..$^{\mathbf{1} 8}$ These reported biotransformation approaches suffered frequently from long reaction time, relatively low yields and troublesome purification procedures. ${ }^{9}$

Recent rapid developments in metabolic engineering by rewiring cellular metabolism provide an attractive alternative approach for producing plant terpenoids. ${ }^{\mathbf{6}, \mathbf{1 0}, 11}$ Saccharomyces cerevisiae has been widely used in terpenoid biosynthesis because it is generally regarded as safe (GRAS), ${ }^{\mathbf{1 0}}$ industrially robust and able to functionally express eukaryotic cytochrome P450 enzymes. ${ }^{12}$ There are many discussions about terpenoid production through metabolic engineering of $S$. cerevisiae at hierarchical levels of genetic manipulation tools, biological parts, pathways, organelles and systems. ${ }^{10,12-15}$ Although significant progresses have been achieved in the past decades, there are still a lot of efforts to be made.

In $S$. cerevisiae, the mevalonate (MVA) pathway is naturally tightly regulated at transcriptional and post-transcriptional levels, limiting the overall metabolic flux for sesquiterpene production. To increase the target sesquiterpene accumulation, genetic modifications that block the competition branch flux could be considered. The squalene synthase (ERG9) is a branchpoint enzyme in the mevalonate (MVA) pathway. ${ }^{16-18}$ As sterols are essential for yeast cells, so it is not feasible to thoroughly knock out squalene synthase (ERG9). Down-regulating the expression of ERG9 by weakening its promoter is an alternative way. In addition, the ROX1 is a transcription factor that inhibits expression of hypoxia-induced genes in the presence of oxygen and also represses target genes during osmotic stress. ${ }^{19}$ Previous study showed that transcriptional regulation of ROX1 mediates the transcriptional regulation of ERG genes. Especially, ERG9 could be activated by ROX1 at the transcription level. ${ }^{20}$

In this study, we constructed and optimized the (+)-nootkatone biosynthesis gene cluster in $S$. cerevisiae to develop a new yeast-based platform for the biosynthesis of $(+)$-valencene and its related sesquiterpenes, combining the disruption of $R O X 1$ gene, the repression of $E R G 9$ through 45 -bp deletion in its promoter, and the overexpression of a truncated version of HMG-CoA reductase 1 (tHMGR) (Scheme 1). Moreover, the carbon sources in the induction medium, the culture conditions and promoters of HPO and AtCPR were investigated to intensify the valencene and its related sesquiterpenes productivities.

\section{Material and methods}

\subsection{General}

DNA polymerase of PrimeSTAR HS was purchased from TaKaRa (Dalian, China). KOD FX DNA polymerase was from Toyobo Co.
Ltd. (Osaka, Japan). Restriction enzymes and T4 DNA ligase were bought from Fermentas of Thermo Fisher Scientific (Pittsburgh, PA, USA). DNA preparations kits for plasmid extraction and DNA purification were purchased from Tiangen (Beijing, China). (+)-Valencene, $\beta$-nootkatol, $(+)$-nootkatone and isolongifolene were provided by Tokyo Chemical Industry Co. Ltd. (TCI, Tokyo, Japan). For all other procedures, the highest purity grade chemicals were used.

\subsection{Strains, media and genetic materials}

E. coli $\mathrm{DH} 5 \alpha$ was used for gene cloning and plasmid maintenance. All recombinant $E$. coli cells were cultured in LuriaBertani (LB) medium with appropriate antibiotics $(100 \mu \mathrm{g}$ $\mathrm{mL}^{-1}$ ampicillin). All recombinant $S$. cerevisiae strains in this study were constructed from BY4741, BJ5464 or CEN·PK2-1Ca. Complete medium of yeast extract peptone dextrose (YPD, containing $1 \%(\mathrm{w} / \mathrm{v})$ yeast extract, $2 \%(\mathrm{w} / \mathrm{v})$ peptone and $2 \%(\mathrm{w} /$ v) D-glucose) was used for yeast cultivation. Engineered yeast strains were grown in minimal synthetic defined (SD) medium (Clontech, Mountain View, USA), in which leucine and/or uracil were omitted for auxotrophic selection. ${ }^{21,22}$ For the expression of galactose-inducible genes, SG, SGR and SGG medium were used, in which the SD medium was changed as the medium containing $2 \%(\mathrm{w} / \mathrm{v})$ galactose instead of glucose, or $2 \%(\mathrm{w} / \mathrm{v})$ galactose supplemented with $0.7 \%(\mathrm{w} / \mathrm{v})$ raffinose, or $2 \%(\mathrm{w} / \mathrm{v})$ galactose combined with $10 \%(\mathrm{w} / \mathrm{v})$ glycerol, respectively.

All heterologous genes used in this study were synthesized by Sangon Biotech (Shanghai, China) with codon optimization for expression in $S$. cerevisiae. The truncated version of HMG1 (tHMGR), alcohol dehydrogenase isozymes (ADH1 and ADH3) were amplified from CEN·PK2-1Ca genomic DNA. Genes used in this study are listed in Table S1. $\uparrow$ Plasmids and strains used in this work are listed in Tables $\mathrm{S} 2$ and $\mathrm{S} 3, \dagger$ respectively.

\subsection{Cloning and integration of pathway in S. cerevisiae}

The assembly of synthetic operon in YEp352 was performed according to the BioBrick principles ${ }^{23}$ described by Zelcbuch et $a .^{24}$ To further simplify the cloning process, a seamless, recombination-based cloning strategy was applied for the synthetic operon construction in YEplac181 using the ClonExpress II One Step Cloning Kit (Vazyme, Nanjing, China). The knockout of ROX1 and knockdown of ERG9 were achieved via CRISPR/Cas9 technologies. ${ }^{25}$ For the CRISPR genome editing, yeast cells were pre-transformed with p414-TEF1p-Cas9-CYC1t plasmid (Addgene). All the PCR products were analyzed on $1 \%$ agarose gels and positive colonies were grown overnight for plasmid extraction using the Tianprep Rapid Mini Plasmid Kit (Tiangen, Beijing China) according to the manufacture's instructions. All clones were verified through the expression cassette sequencing (Sangon, China). The constructed plasmids containing the whole expression operon were chemically transformed into the yeast by $S$. cerevisiae EasyComp ${ }^{\mathrm{TM}}$ Transformation Kit (Invitrogen, CA, United States) and aliquots were plated on the corresponding auxotrophic minimal media. Table $\mathrm{S} 4 \dagger$ lists the primers used to construct these plasmids and strains. 


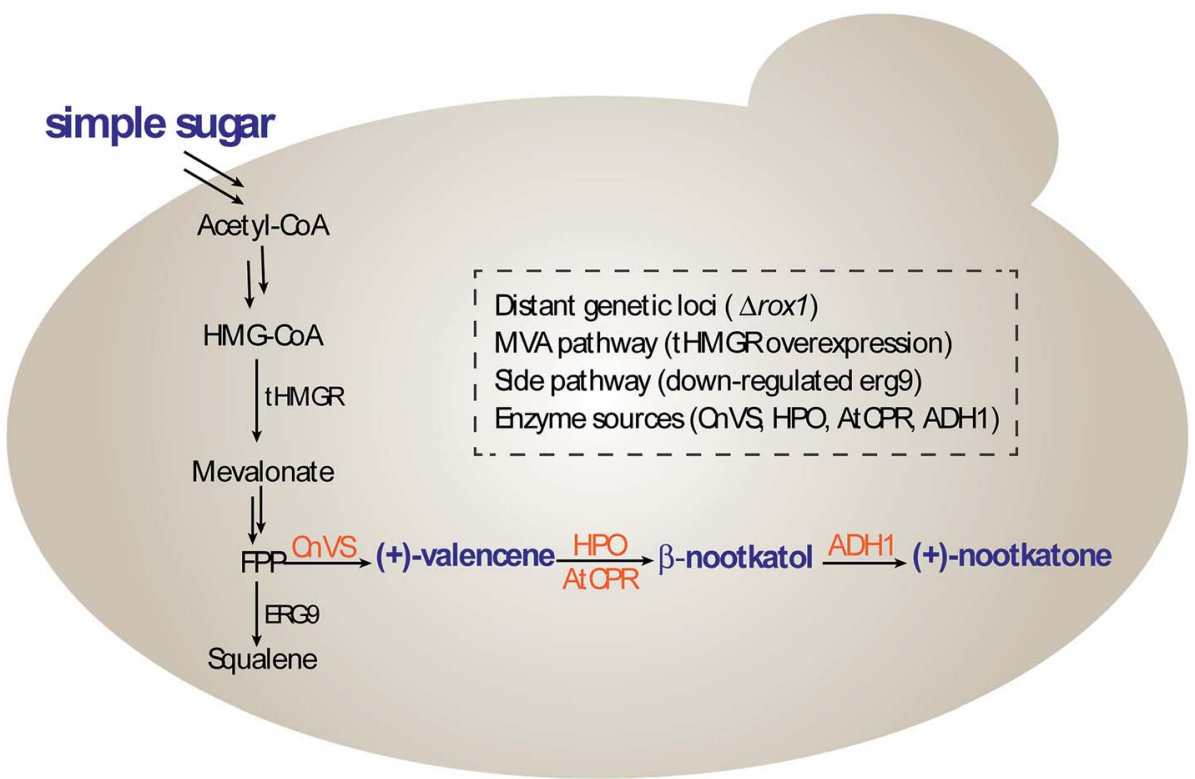

Scheme $1(+)$-Nootkatone biosynthesis pathway in S. cerevisiae.

\subsection{Resting cell assays for $\beta$-nootkatol and (+)-nootkatone production}

Recombinant yeast strains transformed freshly or from $-80{ }^{\circ} \mathrm{C}$ freezer were cultivated on SD plates at $30{ }^{\circ} \mathrm{C}$ for two days. The recombinant single yeast colonies were inoculated into $15 \mathrm{~mL}$ tubes containing $5 \mathrm{~mL}$ of $\mathrm{SD}$ medium supplemented with appropriate amino acids for auxotrophic selection. Cultivation of strains $\left(\mathrm{OD}_{600} \approx 1\right.$ to 2$)$ was scaled up to $50 \mathrm{~mL}$ of total volume in $250 \mathrm{~mL}$ baffled culture flasks to a starter $\mathrm{OD}_{600}$ of 0.1 . When cell density $\left(\mathrm{OD}_{600}\right)$ reached about 3.0 after incubation for several hours, cells were recovered by centrifugation at $1060 \times g$ for $10 \mathrm{~min}$ and resuspended in $50 \mathrm{~mL}$ of SG minimal medium. After $8 \mathrm{~h}$ induction, $150 \mathrm{OD}_{600}$ units of cell pellets were harvested and transferred to sterilized $20 \mathrm{~mL}$ tubes containing $1 \mathrm{~mL}$ of $50 \mathrm{mM}$ potassium phosphate buffer $\left(\mathrm{KP}_{\mathrm{i}}, \mathrm{pH}\right.$ 7.4). The resting cell assays were started by the addition of $20 \mu \mathrm{L}$ of $(+)$-valencene stock solutions (100 mM (+)-valencene and 1\% Triton X-100 (v/v) dissolved in DMSO). Tubes containing cell suspensions were incubated for $18 \mathrm{~h}$. All cells were cultured at $30^{\circ} \mathrm{C}, 200 \mathrm{rpm}$. Samples were taken and extracted into GC vials for further analysis.

\subsection{Bi-phasic batch cultivation in shake flasks}

Pre-cultures of the respective strains were grown for $24-30 \mathrm{~h}$ at $30{ }^{\circ} \mathrm{C}, 200 \mathrm{rpm}$ in $5 \mathrm{~mL} \mathrm{SD}$ medium. The seed cultures were inoculated to an $\mathrm{OD}_{600}$ of 0.05 and grown at $30{ }^{\circ} \mathrm{C}$ and $200 \mathrm{rpm}$ in $50 \mathrm{~mL}$ baffled shake flasks containing $10 \mathrm{~mL}$ SD medium. At an $\mathrm{OD}_{600}$ of about $0.8-1.0$, cells were harvested by centrifugation at $1060 \times g$ for $10 \mathrm{~min}$ and resuspended in $10 \mathrm{~mL}$ of SG, SGR or SGG medium combined with $2 \mathrm{~mL}$ of $n$-dodecane. ${ }^{26}$ The biocatalysis was performed at 25 or $30{ }^{\circ} \mathrm{C}$ under shaking at $200 \mathrm{rpm}$ for different hours. $500 \mu \mathrm{L}$ of immiscible $n$-dodecane layer was taken out at $24,48,72$ and $96 \mathrm{~h}$ and added with $500 \mu \mathrm{L}$ of ethyl acetate for GC analysis.

\subsection{Analysis of (+)-valencene, $\beta$-nootkatol and $(+)$-nootkatone}

For resting cell assays, the (+)-valencene, $\beta$-nootkatol and $(+)$-nootkatone were extracted using equal volume of ethyl acetate. The mixture was vortexed at room temperature for $30 \mathrm{~min}$ and centrifuged. ${ }^{27} 500 \mu \mathrm{L}$ of the top organic layer was transferred into a new tube containing $500 \mu \mathrm{L}$ of ethyl acetate. For bi-phasic fermentation, $500 \mu \mathrm{L}$ of $n$-dodecane layer was taken out and mixed with equal volume of ethyl acetate. Samples were filtered into GC vials through $0.22 \mu \mathrm{m}$ sterile filter. The concentrations of (+)-valencene, $\beta$-nootkatol and $(+)$-nootkatone were expressed as microgram per liter $\left(\mathrm{mg} \mathrm{L}^{-1}\right.$ ethyl acetate or $\mathrm{mg} \mathrm{L}^{-1}$ cell culture).

Analysis of the sesquiterpenes were determined by gas chromatography (GC) using a Hewlett-Packard 7890 Gas Chromatography (Agilent) equipped with a flame ionization detector (FID). An HP-5 column (crosslinked 5\% Ph-Me siloxane; $30 \mathrm{~m} \times$ $0.32 \mathrm{~mm} \times 0.25 \mu \mathrm{m}$ ) was used with hydrogen as carrier gas. The temperatures of injector and detector were set as $250{ }^{\circ} \mathrm{C}$ and $320{ }^{\circ} \mathrm{C}$, respectively. During analysis, $1 \mu \mathrm{L}$ of sample was injected with a split ratio of $30: 1$ at a rate of $0.4 \mathrm{~mL} \mathrm{~min}^{-1}$ in constant flow mode ( $49 \mathrm{~cm} \mathrm{~s}^{-1}$ linear velocity). The initial oven temperature was set to $100{ }^{\circ} \mathrm{C}$ for $10 \mathrm{~min}$ with a ramp rate for separation as $10{ }^{\circ} \mathrm{C}$ per min, and maintained at $200{ }^{\circ} \mathrm{C}$ for 8 min. ${ }^{16}$ Analyses were carried out in triplicate, and concentrations were determined using $50 \mu \mathrm{M}$ isolongifolene (Sigma Aldrich, St. Louis, MO) as an internal standard.

Analysis by GC/MS using a GC/MS-HP7890 (Agilent) equipped with a 5975C series mass selective detector (MSD). Same analysis methods were used as GC-FID detection. MS data were recorded at $70 \mathrm{eV}(\mathrm{EI}), \mathrm{m} / z$ (rel. intensity in \%) as TIC, total ion current. The data were collected in full scan mode $(\mathrm{m} / \mathrm{z} 50-650)$. Compounds in the samples were identified by the comparison of retention time and mass GC/MS spectra to the commercially 
available chemical standards and mass spectra data of the NIST Standard Reference Database.

\section{Results and discussion}

\section{1 (+)-Valencene hydroxylation using resting cells}

Firstly, two reported cytochrome P450s (HPO from Hyoscyamus muticus $^{28}$ and CnVO from Callitropsis nootkatensis ${ }^{29}$ ) were investigated for (+)-valencene hydroxylation. The coding genes were separately introduced into the YEplac181 under the control of galactose inducible promoter of $P_{\mathrm{GAL} 1}$. The cytochrome P450 reductase (CPR) from Arabidopsis thaliana was cloned into the vector of YEp352 containing a GAL1 promoter, generating p352-CPR. To this end, biohydroxylation of (+)-valencene in $S$. cerevisiae CEN·PK2-1Ca expressing different cytochrome P450s in combination with CPR were performed. $150 \mathrm{OD}_{600}$ units of recombinant resting cells were collected and resuspended in $1 \mathrm{~mL} 50 \mathrm{mM} \mathrm{KP}_{\mathrm{i}}$ buffer containing $20 \mu \mathrm{L}$ of $(+)$-valencene stock solution. After $18 \mathrm{~h}$ at $30{ }^{\circ} \mathrm{C} 200 \mathrm{rpm}$, the products were extracted using ethyl acetate and detected by GCFID (Fig. 1A). The GC-MS analysis confirmed the $\beta$-nootkatol and $(+)$-nootkatone by comparison of the mass fragmentation pattern to an authentic standard chemicals (Fig. 1B). No $\beta$ nootkatol was detected in the extract of the PK2-C strain containing the empty plasmids. PK2-01 containing HPO/AtCPR expression cassettes catalyzed (+)-valencene hydroxylation to $\beta$-nootkatol and (+)-nootkatone, detected at $48.4 \pm 4.5$ and $8.9 \pm$ $1.6 \mathrm{mg} \mathrm{L}^{-1}$ ethyl acetate corresponding to a $13.02 \%\left(\mathrm{~mol} \mathrm{~mol}^{-1}\right)$ conversion of substrate to product (Fig. 2A). The whole-cell biotransformation of (+)-valencene in PK2-01 was not consistent with the previous reported results that HPO failed to synthesize (+)-nootkatone in $S$. cerevisiae, although the engineered strain could catalyze the hydroxylation of $(+)$-valencene to $\beta$-nootkatol. ${ }^{28,30}$ For the CnVO, formations of $\beta$-nootkatol and $(+)$-nootkatone was reduced to about $10-15 \%$ of those catalyzed by HPO (Fig. 2A). In this study, effects of double mutation combinations of V482I/A484I in HPO were also investigated. Results showed that no higher titers of $\beta$-nootkatol were obtained, indicating that in vitro enzyme-kinetic data is often not verifiable in practice. ${ }^{28,31}$

When the recombinant PK2-01 was stored in $-80{ }^{\circ} \mathrm{C}$ ultralow temperature freezer for only one week, the total terpenoids production by the recovered strain decreased dramatically about $65 \%$. Further kept at the same conditions, almost $80 \%$ of $(+)$-valencene hydroxylation activity was lost (Fig. 2B). In order to conquer the instability, the $H P O$ and $A t C P R$ were both introduced into $S$. cerevisiae CEN·PK2-1 Ca under the control of galactose inducible promoter of $P_{\mathrm{GAL} 1}$ using the plasmids of YEplac181 or YEp352, denoted as PK2-30 and PK2-31, respectively (Fig. 3A). Surprisingly, great improvements of $\beta$-nootkatol and (+)-nootkatone production were obtained as $108.2 \pm 4.5$ and $19.1 \pm 2.1 \mathrm{mg} \mathrm{L}^{-1}$ ethyl acetate, respectively, when the two HPO and AtCPR expression cassettes were both located on YEp352. While using YEplac181 as construction backbone, no similar results were observed.

Considering the fact that $19.1 \mathrm{mg} \mathrm{L} \mathrm{L}^{-1}$ ethyl acetate of (+)-nootkatone was detected in PK2-31, we speculated that the intrinsic alcohol dehydrogenase (ADH) activity accomplishes this conversion from $\beta$-nootkatol. Two different $A D H$ genes ( $A D H 1$ and $A D H 3$ ) were selected for overexpression under the constitutive promoter of $\mathrm{P}_{T D H 3}$. When co-expressed with ADH1, (+)-nootkatone production was dramatically increased by $2.4-$ fold in the newly created strain PK2-32 as compared to PK2-31. Surprisingly, great improvement of $\beta$-nootkatol production was also observed (170.5 $\pm 15.5 \mathrm{mg} \mathrm{L}^{-1}$ ethyl acetate, Fig. $\left.3 \mathrm{~A}\right)$. The total oxidation rate of (+)-valencene to terpenoids by PK2-32 reached as $49.1 \%\left(\mathrm{~mol} \mathrm{~mol}^{-1}\right)$, which was higher than that by Y. lipolytica 2-2ab previously reported. ${ }^{8}$ However, strain PK2-33 containing ADH3 showed decreases for both $\beta$-nootkatol and $(+)$-nootkatone production compared to PK2-32. ADH1 is generally regarded as primarily responsible for the $\mathrm{NAD}^{+}$ regeneration from NADH through the acetaldehyde reduction, ${ }^{32-34}$ which is beneficial for the $\beta$-nootkatol oxidation to (+)-nootkatone.

The capabilities of whole-cell (+)-valencene oxidation in three frequently employed industrial $S$. cerevisiae strains were further evaluated. The host strain CEN·PK2-1 Ca harboring p352-A1HC (PK2-32) produced the highest amounts of $\beta$-nootkatol and $(+)$-nootkatone, followed by the strain of BJ-32 (BJ5464 containing p352-A1HC). The lowest $\beta$-nootkatol and (+)-nootkatone production were monitored in S288c derived strain of BY-32 (10.3 \pm 0.8 and $3.7 \pm 0.2 \mathrm{mg} \mathrm{L}^{-1}$ ethyl acetate, respectively). The premnaspirodiene oxygenase (encoded by HPO), according to Marjohn (2016) ${ }^{35}$ is anchored in the endoplasmic reticulum (ER) membrane. The deletion of PEP4 and PRB1 in the yeast strain BJ5464 disordered the vacuolar degradation, which is important for heterologous ER resident protein expression..$^{36}$ This might be the main reason that less than half of amounts of $\beta$-nootkatol and (+)-nootkatone (45.8 and 36\%, respectively) were detected in BJ-32 than did in PK2-32. Whole genome sequencing of $S$. cerevisiae revealed that CEN.PK strains possessed significant higher abilities in galactose uptake and metabolism, and the great higher expression of HMG-CoA reductase (encoded by HMG1) compared to S288c. ${ }^{18}$

The storage stability of PK2-32 was also determined by incubating at $-80^{\circ} \mathrm{C}$ freezer. After 8 months incubation, almost $85 \%$ of $(+)$-valencene hydroxylation activities were still retained (Fig. 3B).

\subsection{In-situ production of (+)-valencene from FPP}

To synthesize (+)-valencene from FPP in S. cerevisiae strains, the open-reading frame of CnVS from Callitropsis nootkatensis was cloned under the control of TDH3 promoter, yielding p181-V1 and transformed into CEN·PK2-1Ca. After 2 days fermentation, $2.6 \pm 0.2 \mathrm{mg} \mathrm{L}^{-1}$ cell culture of (+)-valencene was detected in $10 \mathrm{~mL}$ cultures overlaid with $20 \%(\mathrm{v} / \mathrm{v}) n$-dodecane in conical flasks (Fig. 4). No (+)-valencene was detected from a CEN·PK21Ca culture containing an empty plasmid (data not shown). It was reported that the CnVS expressed under the control of inducible promoter $\mathrm{P}_{G A L 1}$ in WAT11 only led to $1.36 \mathrm{mg} \mathrm{L}^{-1}$ $(+)$-valencene. ${ }^{37}$ The WAT11 strain was engineered with NADPHcytochrome $\mathrm{P} 450$ reductase gene but not optimized for sesquiterpene production. ${ }^{38}$ As previously studied, the ergosterol 
(A)

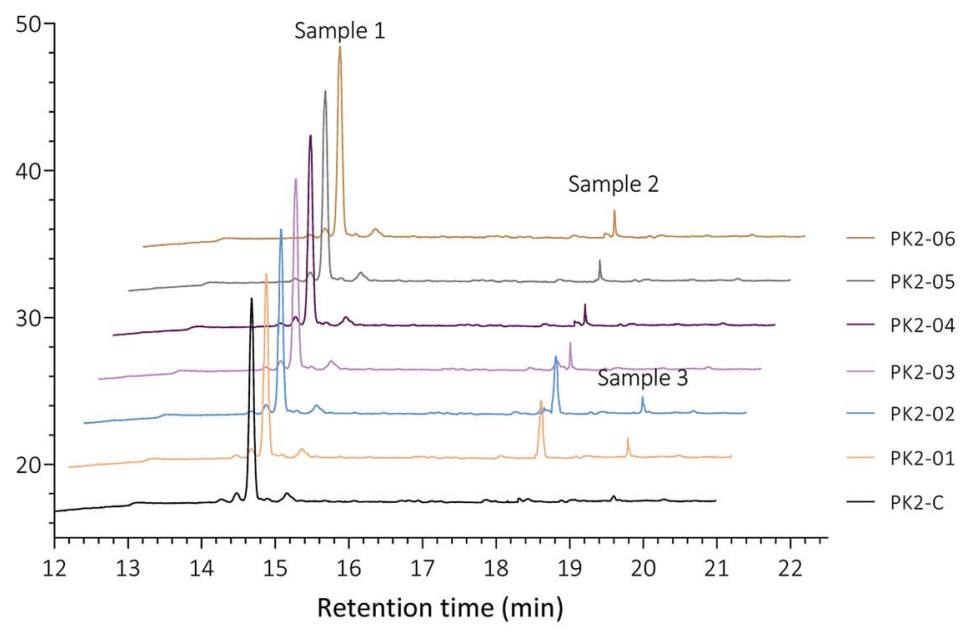

(B)
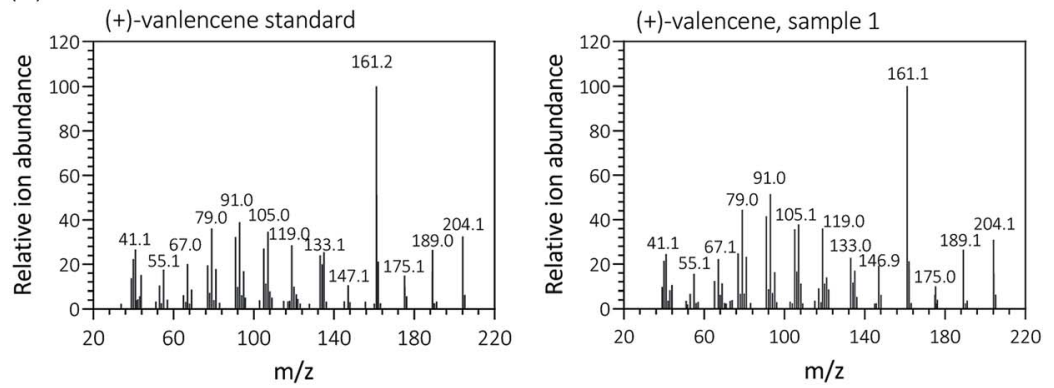

(C)
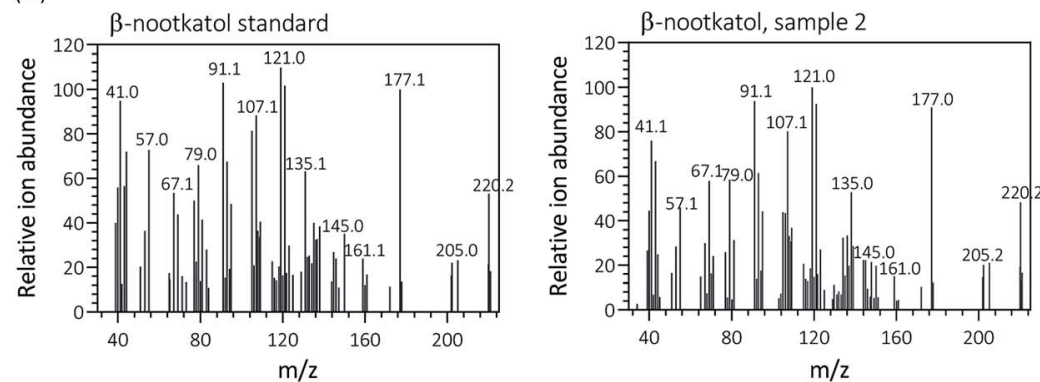

(D)
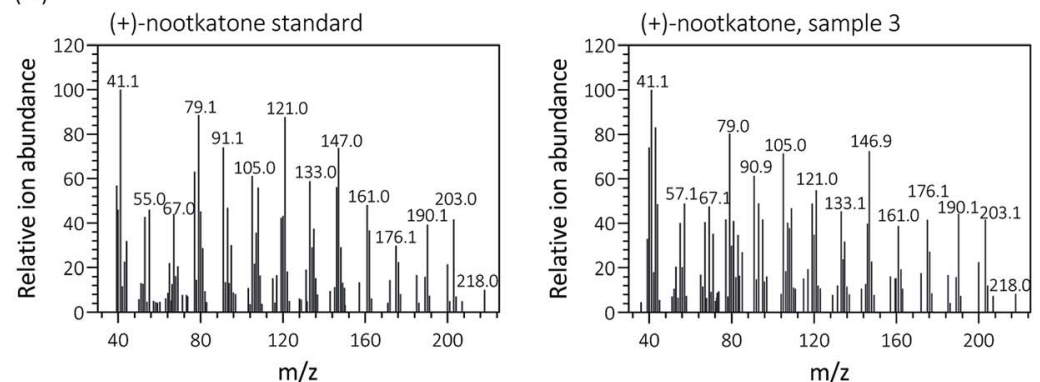

Fig. 1 Analysis and identification of the hydroxylation of (+)-valencene (sample 1) to $\beta$-nootkanol (sample 2) and (+)-nootkatone (sample 3) by different S. cerevisiae strains expressing HPO, CnVO or their mutants, respectively. (A) GC-FID chromatogram patterns of the products obtained by $150 \mathrm{OD}_{600}$ yeast cells incubated with $2 \mathrm{mM}(+)$-valencene at $30{ }^{\circ} \mathrm{C}$ for $18 \mathrm{~h}$. Retention times of (+)-valencene, $\beta$-nootkanol and (+)-nootkatone were $14.639 \mathrm{~min}, 18.349 \mathrm{~min}$ and $19.540 \mathrm{~min}$, respectively. Mass spectra of the products are compared with mass patterns of authentic standards (+)-valencene (B), $\beta$-nootkatol (C) and (+)-nootkatone (D) standard. 
(A)

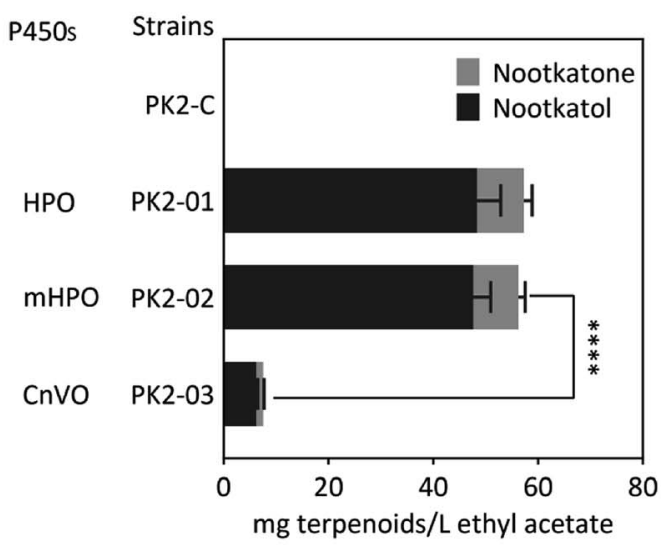

(B)

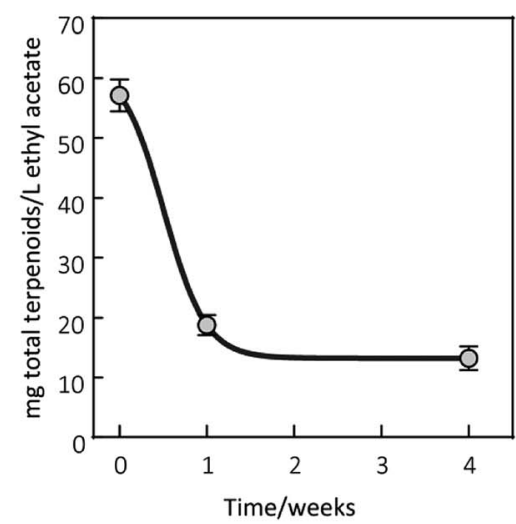

Fig. 2 (A) Resting cell assays of (+)-valencene hydroxylation to $\beta$-nootkanol and (+)-nootkatone using different cytochrome P450s under the control of galactose inducible promoter of $\mathrm{P}_{G A L 1}$ in YEplac181 in S. cerevisiae. Amino acid exchange of V482I/A484I (mHPO) in HPO was achieved through site-directed mutagenesis. No $\beta$-nootkanol or $(+)$-nootkatone was detected in strain PK2-C. The asterisk (****) indicates statistically significant differences in terpenoids formation ( $p<0.0001$, student's $t$-test). (B) Changes of ( + )-valencene oxidation capabilities in yeast PK2-01 when cells incubated in glycerol stocks at during one month of storage. Recombinant yeast strains transformed freshly or from $-80{ }^{\circ} \mathrm{C}$ freezer were cultivated on SD plates at $30{ }^{\circ} \mathrm{C}$ for two days. Then the recombinant single yeast colonies were inoculated into tubes containing $5 \mathrm{~mL}$ of SD medium supplemented with appropriate amino acids for auxotrophic selection. Cultivation of strains $\left(\mathrm{OD}_{600} \approx 1\right.$ to 2$)$ was scaled up to $50 \mathrm{~mL}$ of total volume in $250 \mathrm{~mL}$ baffled culture flasks to a starter $O D_{600}$ of 0.1 , which was prepared for subsequent resting cell assays. The total terpenoids was calculated as the sum of $\beta$-nootkanol and $(+)$-nootkatone in $\mathrm{mg} \mathrm{L}^{-1}$ ethyl acetate. All experiments were performed in triplicates.

biosynthetic pathway enrichment was detected in the popular production host of $S$. cerevisiae CEN·PK strains ${ }^{18}$ which might supply higher FPP concentration in vivo and showed stronger capability in (+)-valencene biosynthesis.

To enhance yields, down-regulation of $E R G 9$ together with knockout of negative transcriptional regulator of ROX1 was applied to increase metabolic flux toward (+)-valencene synthesis, generating PK2-12. This strategy resulted in a 3.8-fold improvement in the (+)-valencene content compared to PK2-11. Then we overexpressed the truncated HMG1 gene (tHMGR), which is a major rate limiting enzyme in the MVA pathway, ${ }^{22,39-41}$ under the control of the TDH3 promoter and integrated the entire overexpression cassette into p181-V1. As expected, there was a further improvement in ( + -)valencene production, reaching titer of $16.8 \pm 1.2 \mathrm{mg} \mathrm{L}^{-1}$ yeast culture (PK2-13 in Fig. 4). Considering the toxic effects of (+)-valencene to $S$. cerevisiae, ${ }^{42}$ we placed the $(+)$-valencene synthase gene under a weaker endogenous promoter of TEF1 $\left(\mathrm{P}_{T E F 1}\right)$, yielding the recombinant yeast of PK2-14. Also, the expression vector p181-V1HV2 containing tHMGR and two CnVS $\left(P_{T D H 3}\right.$ and $\mathrm{P}_{T E F 1}$ controlled, respectively) expression cassettes, was also constructed and transformed into yeast to generate PK2-15. The (+)-valencene production was surprisingly enhanced to $28.9 \pm$ $1.9 \mathrm{mg} \mathrm{L}^{-1}$ cell culture in PK2-14. $\mathrm{P}_{T D H 3}$ and $\mathrm{P}_{T E F 1}$ are the common-used constitutive promoters in the yeast $S$. cerevisiae. There is a general view that the promoter strength of $\mathrm{P}_{T D H 3}$ is
(A)

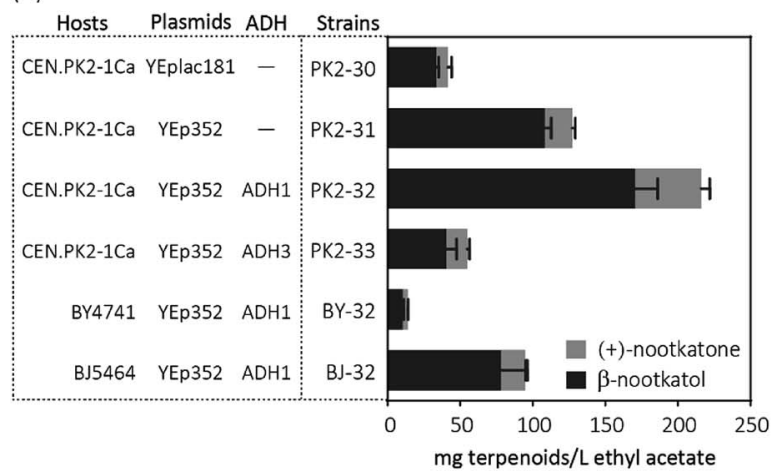

(B)

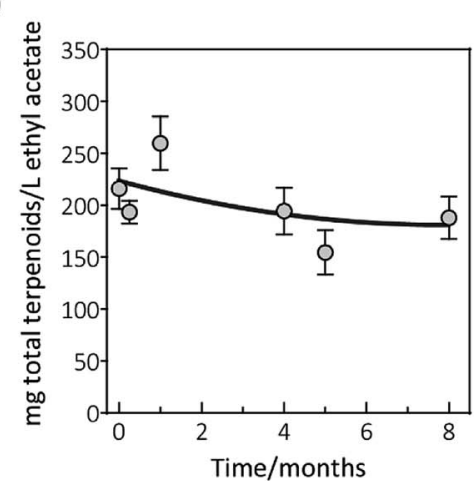

Fig. 3 (A) Resting cell assays of (+)-valencene hydroxylation to $\beta$-nootkanol and (+)-nootkatone using different constructs in S. cerevisiae. Hosts (CEN - PK2-1Ca, BY4741 and BJ5464), constructed based on backbone (YEplac181 and YEp352) and alcohol dehydrogenase isozymes (ADH1 and ADH3) were compared. (B) Changes of ( + )-valencene oxidation capabilities in yeast PK2-32 when cells incubated over a period of 8 months. The total terpenoids was calculated as the sum of $\beta$-nootkanol and $(+)$-nootkatone in $\mathrm{mg} \mathrm{L}^{-1}$ ethyl acetate. Data is representative of triplicate determinations and error bars indicate standard deviations. 


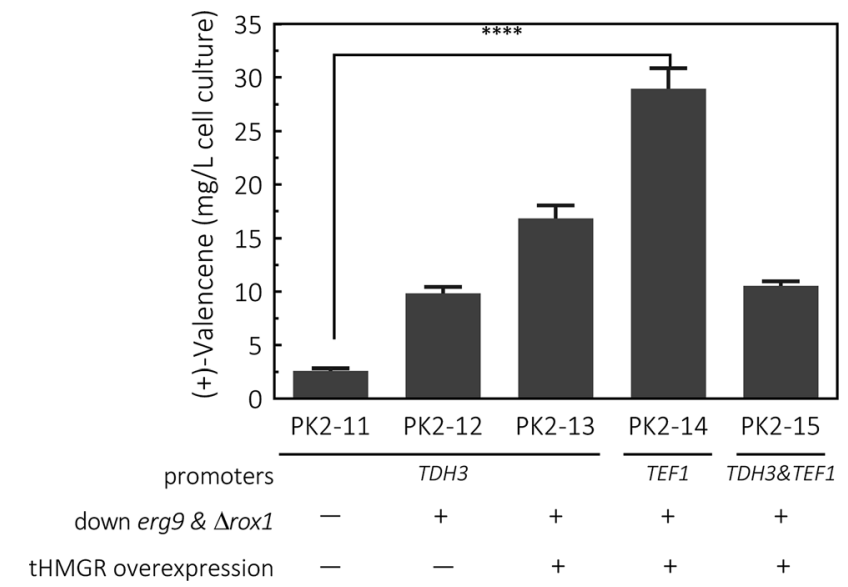

Fig. 4 De novo production of (+)-valencene in different $S$. cerevisiae strains cultured in $50 \mathrm{~mL}$ flask cultures containing $10 \mathrm{~mL}$ containing $20 \% n$-dodecane. The valencene synthase (CnVS) from C. nootkatensis was cloned under different promoters of TDH3 and TEF1. The platform was based on CEN.PK2-1Ca combining the suppression of erg9, knockout of the negative regulator rox1 and overexpression of truncated form of HMG1 gene (tHMGR). Error bars represent standard deviation from a triplicate analysis. The asterisk $(* * * *)$ indicates statistically significant differences in terpenoids formation $(p<0.0001$, student's $t$-test).

stronger than that of $\mathrm{P}_{T E F 1}$ under different growth phases. ${ }^{43,44}$ However, the high-level expression of enzymes in some certain pathway might result in detrimental effects on cell growth. ${ }^{45}$ Actually, the final cell density of $\mathrm{OD}_{600}$ for PK2-14 was dramatically increased to 5.23 from 3.77 for PK2-13, indicating the product potential toxicity inhibited the cell growth and $(+)$-valencene synthesis. ${ }^{42}$ This might possibly explain the less productivity of cell factories of PK2-13. The significance decrease of $63.6 \%$ in $(+)$-valencene levels was observed when two CnVS expression cassettes existed in one cell (PK2-15) compared to PK2-14, which further demonstrated that the upregulation of CnVS expression was not beneficial to the $(+)$-valencene accumulation. These results provide insights in promoter selection for practical application in sesquiterpenoids cell factory construction.

\subsection{De novo production of (+)-valencene related terpenoids through culture condition optimization}

Having enhanced the (+)-valencene accumulation through stepwise metabolic engineering approaches, the combination of $(+)$-valencene production from FPP and $(+)$-valencene oxidation to $\beta$-nootkatol and (+)-nootkatone was carried out. Coexpression of CnVS with HPO, AtCPR and ADH1 in the metabolic altered yeast CEN.PK2-1Ca mutant created a new yeast strain designated as PK2-24.

Yeast can grow on a variety of carbon sources including fermentable and nonfermentable substances. Raffinose is a trisaccharide composed of galactose, glucose and fructose. Usually raffinose is added to minimal medium containing galactose for protein expression induction. ${ }^{27}$ As an organic compound, glycerol assimilation can occur in the presence of galactose in yeast. Earlier work indicated that the glycerol or raffinose addition might be favor to noscapine biosynthesis. ${ }^{6,46}$ We first explored the effects of galactose, raffinose and glycerol as carbon sources on the production of $(+)$-valencene related terpenoids from PK2-24. In $50 \mathrm{~mL}$ bi-phasic shake flask cultures, supplementation of raffinose or glycerol resulted in more efficient synthesis of (+)-valencene and led to statistically significant improvements with about 1.3-fold increase of (+)-valencene titers (Fig. 5A). However, an in-significant decrease in the $\beta$-nootkatol productivities was monitored in the case of raffinose or glycerol addition.

We continued to investigate the roles of temperature and incubation time played in (+)-valencene accumulation in SG
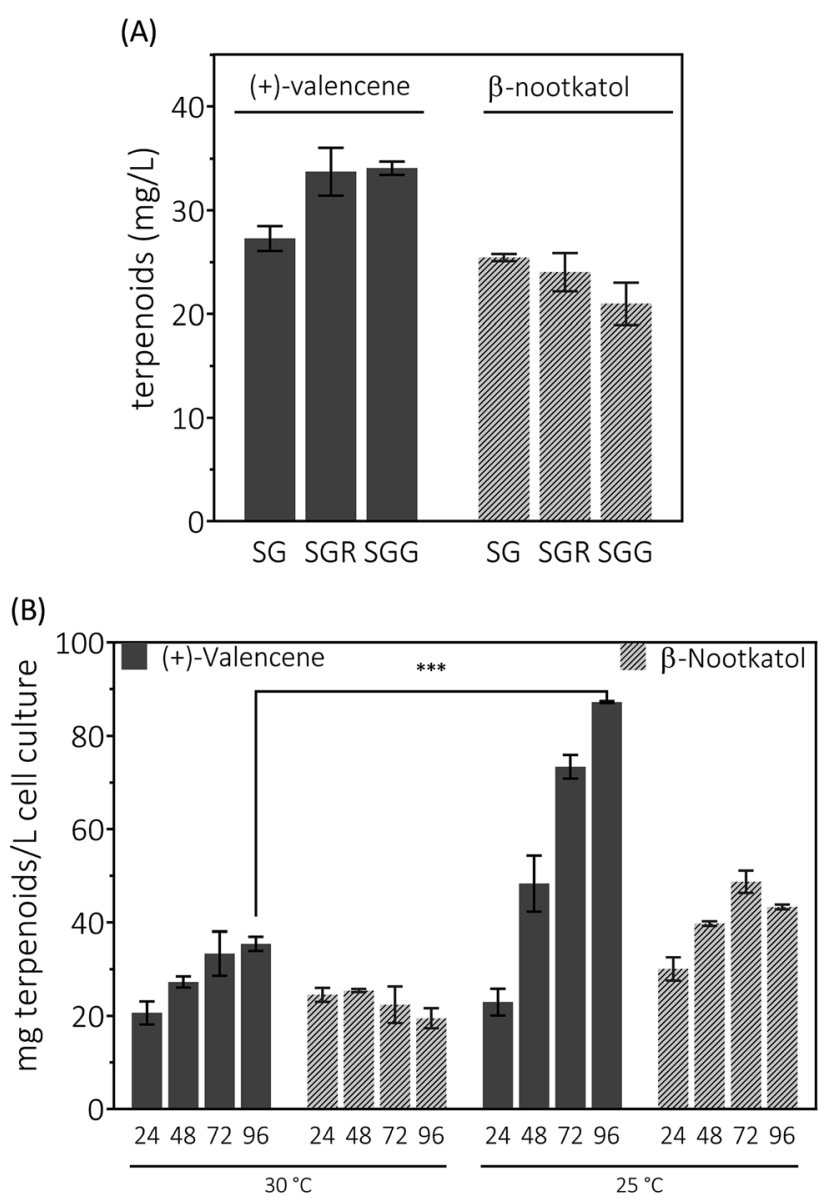

Fig. 5 De novo production of $(+)$-valencene and $\beta$-nootkatol using PK2-24 in $50 \mathrm{~mL}$ bi-phasic conical flask cultures. One $\mu \mathrm{L}$ aliquots of $n-$ dodecane phase for each sample were analyzed by GC-FID. (A) Carbon source in induction medium effects on the products accumulation. Yeasts were cultured in $20 \mathrm{~g} \mathrm{~L}^{-1}$ glucose at $30^{\circ} \mathrm{C}$ for $14-16 \mathrm{~h}$ for cell growth. Cells were collected by centrifugation and transferred into fresh induction medium containing galactose to induce HPO and AtCPR expression, SG (2\% galactose), SGG (2\% galactose and 10\% glycerol) and SGR (2\% galactose and 0.7 raffinose), respectively. (B) Time and temperature responses of product accumulation. 24, 48, 72 and 96 represent the cultivation time in hours. Mean values and standard deviations of biological triplicates are shown. The asterisk $(* * *)$ indicates statistically significant differences in $(+)$-valencene formation ( $p<0.001$, student's $t$-test). 
medium (Fig. 5B). As previous culturing conditions, recombinant cells were cultured at $30{ }^{\circ} \mathrm{C}$. The $(+)$-valencene levels were found to increase up to about 1.7 -fold over $96 \mathrm{~h}$ fermentation time. The $\beta$-nootkatol titers in the $n$-dodecane layer remained generally constant at about 22-24 mg L ${ }^{-1}$ cell culture. However, when PK224 cells shifted to $25{ }^{\circ} \mathrm{C}$, tremendous improvements in $(+)$-valencene levels was observed as culture time elongation (from $22.9 \pm 2.8 \mathrm{mg} \mathrm{L}^{-1}$ at $24 \mathrm{~h}$ to $87.2 \pm 0.2 \mathrm{mg} \mathrm{L}^{-1}$ at $96 \mathrm{~h}$ ). A relatively moderate increase in $\beta$-nootkatol titers was observed in 0-72 $\mathrm{h}$ range, followed by a slight decrease in the final $24 \mathrm{~h}$ cultivation. Lower incubation temperature and longer cultivation time resulted in an increase of the final $(+)$-valencene and $\beta$ nootkatol from $20.6 \pm 2.5$ and $24.5 \pm 1.5$ up to $87.2 \pm 0.2$ and $43.3 \pm 0.5 \mathrm{mg} \mathrm{L}^{-1}$ cell culture, respectively.

Generally speaking, the (+)-valencene contents in $n$-dodecane layer were improved dramatically, and the $\beta$-nootkatol concentration increased by a moderate amount through culture condition optimization. At the end of fermentation, even decreased $\beta$-nootkatol levels were monitored under many culture conditions. The results indicated the activity of HPO

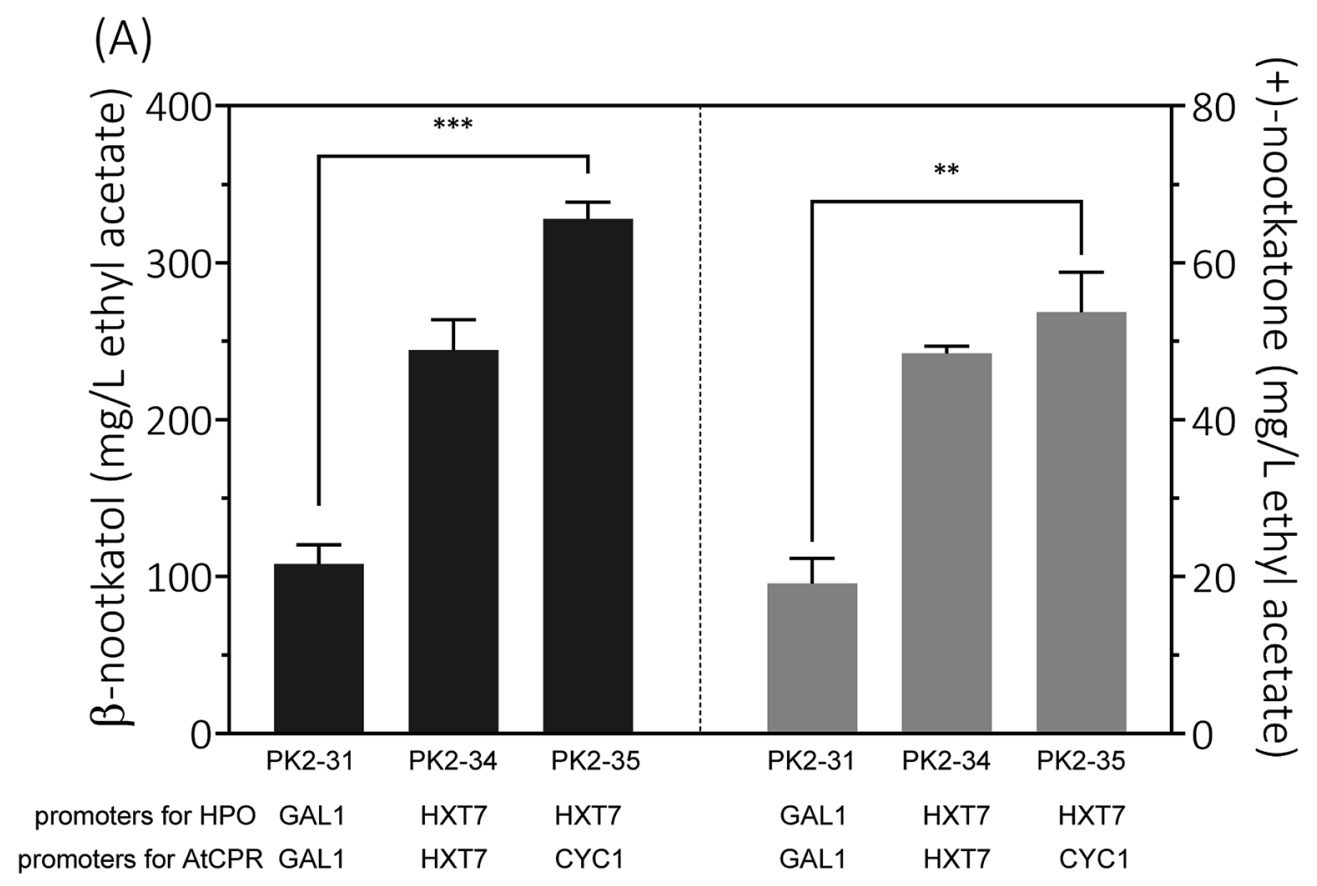

(B)

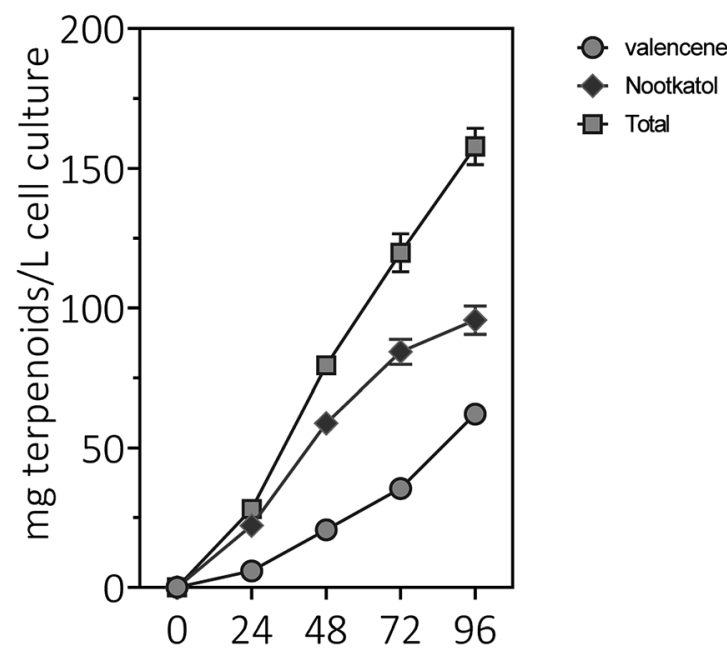

Time (h)

Fig. 6 (A) Resting cell assays of (+)-valencene hydroxylation to $\beta$-nootkanol and (+)-nootkatone using different constructs in S. cerevisiae CEN.PK2-1Ca. Promoters of HPO and AtCPR were noted at the bottom of the diagram. (B) Time responses of product accumulation. 24, 48, 72 and 96 represent the cultivation time in hours with PK2-25 harboring p181-V2H and p352-A1HC3. Mean values and standard deviations of biological triplicates are shown. The asterisk $(* * *)$ indicates statistically significant differences in $\beta$-nootkanol formation $(p<0.001$, student's $t$ test). The asterisk (**) indicates statistically significant differences in $(+)$-nootkatone formation $(p<0.05$, student's $t$-test). 
Table 1 In vivo production of $\beta$-nootkatol and (+)-nootkatone

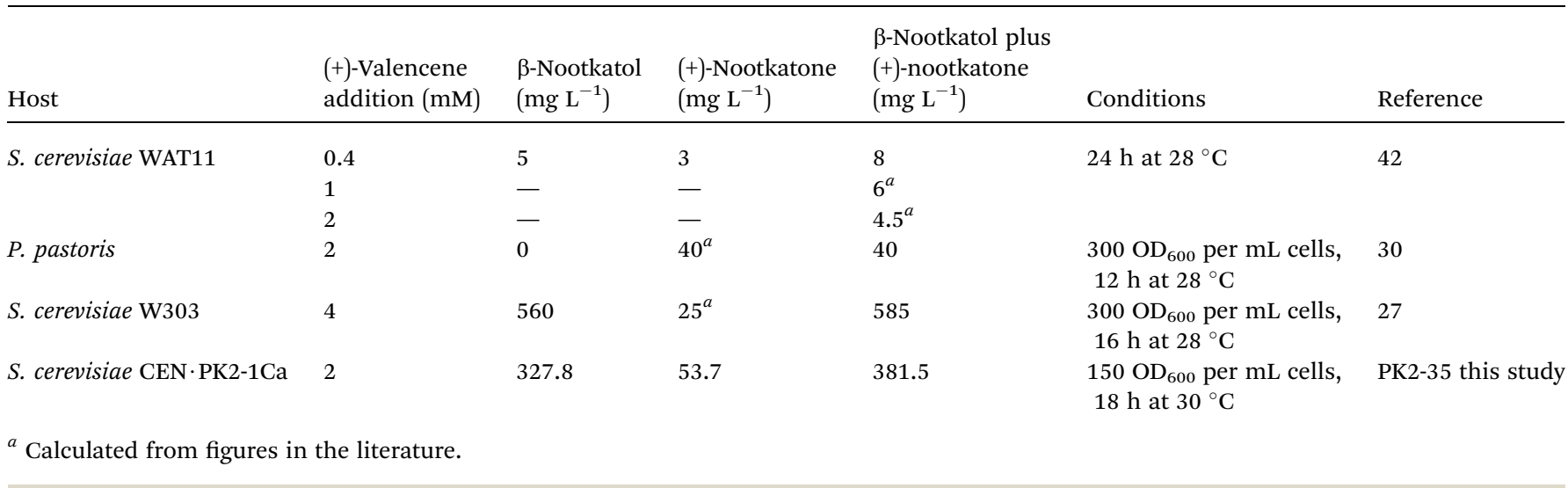

and AtCPR was not sufficient to transform the in situ produced $(+)$-valencene into $\beta$-nootkatol. As many cytochrome P450 enzymes, the instability is a major hurdle for the $(+)$-valencene hydroxylation for industrial processes. Wriessnegger et al. ${ }^{30}$ reported that reduced level of HPO and CPR enzymes were observed with extended cultivation times. Efforts must be made to identify or design proteins with improved stability. ${ }^{47}$ The more disappointing part is that no (+)-nootkatone was detected in the strain PK2-24. The reasons for this might be the accumulation of $(+)$-nootkatone in yeast endomembranes. ${ }^{\mathbf{4 2}}$

\subsection{Improve the level of $\beta$-nootkatol by promoter optimization}

Expression of HPO and CPR from the GAL1 promoter was subjected to galactose induction and glucose inhibition. Considering the facts that (1) the preferred carbon sources for yeast are glucose and fructose, (2) the inducer galactose has a relatively high cost, and (3) glucose-galactose transitions would cause major metabolic changes. In order to develop a glucose-based production system, we changed the promoter of HPO and
AtCPR from GAL1 to $H X T 7$, encoding a hexose transporter. Great improvements of $\beta$-nootkatol and (+)-nootkatone production were observed as $244.3 \pm 19.3$ and $48.4 \pm 0.9 \mathrm{mg} \mathrm{L}^{-1}$ in PK2-34 (Fig. 6A). In consideration of the possible negative effects on genes expression by using the same promoters and terminators for two genes in one plasmid, AtCPR was put under another commonly used promoter (CYC1) in S. cerevisiae, yielding the plasmid p352-HC3. As expectations, the titers of $\beta$-nootkatol and (+)-nootkatone were improved to $327.9 \pm 10.7 \mathrm{mg} \mathrm{L}^{-1}$ and $53.7 \pm 5.1 \mathrm{mg} \mathrm{L}^{-1}$ in PK2-35 (Table 1 ). The total oxidation efficiency of $(+)$-valencene to terpenoids by PK2-35 reached as $87.0 \%\left(\mathrm{~mol} \mathrm{~mol}^{-1}\right)$, which was increased by 3.1-fold compared to PK2-31. This suggested that expressing genes with different promoters was better than that with the same promoters.

Inspired by the prominent effects in resting cell assays, we tried to produce (+)-valencene and its related terpenoids by the recombinant yeast PK2-25 containing p181-V2H and p352A1HC3 through using simple carbon source glucose, which was much cheaper than galactose. As previous optimized culture conditions, the strain PK2-25 was cultured at $25{ }^{\circ} \mathrm{C}$ in SD

Table 2 In situ (+)-valencene related terpenoid production in flask

\begin{tabular}{|c|c|c|c|c|c|c|c|}
\hline Host & Overexpressed enzymes & $\begin{array}{l}(+) \text {-Valencene } \\
\left(\mathrm{mg} \mathrm{L}^{-1}\right)\end{array}$ & $\begin{array}{l}\beta- \\
\text { Nootkatol } \\
\left(\mathrm{mg} \mathrm{L}^{-1}\right)\end{array}$ & $\begin{array}{l}\text { (+)-Nootkatone } \\
\left(\mathrm{mg} \mathrm{L}^{-1}\right)\end{array}$ & $\begin{array}{l}\text { Total } \\
\text { terpenoids } \\
\left(\mathrm{mg} \mathrm{L}^{-1}\right)\end{array}$ & $\begin{array}{l}\text { Terpenoids } \\
\text { (mg } \\
\text { per L per } \\
\left.\text { OD }_{600}\right)\end{array}$ & Reference \\
\hline \multirow[t]{2}{*}{ S. cerevisiae WAT11 } & $\mathrm{VS}^{a}$ & 1.36 & - & - & 1.36 & - & 48 \\
\hline & $\mathrm{VS}^{a}, \mathrm{P} 450 \& \mathrm{CPR}^{b}$ & 0.15 & 0.92 & 0.04 & 1.11 & - & \\
\hline \multirow[t]{2}{*}{ R. sphaeroides } & $\mathrm{VS}^{a}$ & 57.5 & - & - & 57.5 & - & 37 \\
\hline & $\mathrm{VS}^{a}$, MVA operon & 352 & - & - & 352 & - & \\
\hline S. cerevisiae W303 & $\mathrm{VS}^{a}, \mathrm{P} 450 \& \mathrm{CPR}^{b}, \mathrm{tHMG}, \mathrm{ICE} 2$ & $1^{c}$ & 30 & - & 31 & - & 27 \\
\hline S. cerevisiae WAT11 & $\mathrm{VS}^{a}, \mathrm{P} 450$ & 1.305 & 0.116 & 0.144 & 1.565 & - & 29 \\
\hline P. pastoris & $\mathrm{VS}^{a}, \mathrm{P} 450 / \mathrm{CPR}^{b}, \mathrm{RAD} 52$ & $9^{c}$ & 94 & $3^{c}$ & 106 & - & 49 \\
\hline \multirow[t]{3}{*}{ P. pastoris } & $\mathrm{VS}^{a}$ & 51 & - & - & 51 & - & 30 \\
\hline & $\mathrm{VS}^{a}, \mathrm{P} 450 / \mathrm{CPR}^{b}$ & 2 & 8 & 0.3 & 10.3 & - & \\
\hline & $\mathrm{VS}^{a}, \mathrm{P} 450 / \mathrm{CPR}^{b}, \mathrm{ADH} 1, \mathrm{tHMG} 1$ & 7 & 18 & 17 & 42 & $0.86^{c}$ & \\
\hline Y. lipolytica & $\mathrm{VS}^{a}, \mathrm{P} 450 / \mathrm{CPR}^{b}$ tHMG1, ERG20 & 22.8 & - & 0.98 & 23.78 & - & 50 \\
\hline $\begin{array}{l}\text { S. cerevisiae } \mathrm{CEN} \cdot \mathrm{PK} 2- \\
1 \mathrm{Ca}\end{array}$ & $\begin{array}{l}\mathrm{VS}^{a}, \mathrm{P} 450 / \mathrm{CPR}^{b}, \text { ADH1, tHMG1, } \\
\Delta \mathrm{ROX} 1 \text {, down-regulated ERG9 }\end{array}$ & 62 & 96 & - & 158 & 29.64 & $\begin{array}{l}\text { PK2-25 this } \\
\text { study }\end{array}$ \\
\hline
\end{tabular}

${ }^{a}$ Different sources of valencene oxidase were overexpressed in corresponding hosts. ${ }^{b}$ Different sources of cytochrome P450 reductase (CPR) were overexpressed in corresponding hosts. ${ }^{c}$ Calculated from figures in the literature. 
medium. As expected, the yield of $\beta$-nootkatol was increased to $95.7 \pm 5.1 \mathrm{mg} \mathrm{L}{ }^{-1}$ over $96 \mathrm{~h}$, which was nearly 2-fold as compared to PK2-24 (Fig. 6B). At the same time, the production of $(+)$-valencene was $62.1 \pm 1.4 \mathrm{mg} \mathrm{L}^{-1}$. It was obvious that $\beta$ nootkatol accumulated rapidly during $0-72 \mathrm{~h}\left(1.17 \mathrm{mg} \mathrm{L}^{-1} \mathrm{~h}^{-1}\right)$ and increased slowly in last $24 \mathrm{~h}\left(0.47 \mathrm{mg} \mathrm{L}^{-1} \mathrm{~h}^{-1}\right)$. Conversely, the accumulation of (+)-valencene was slow during 0-72 $\mathrm{h}$ (0.49 $\left.\mathrm{mg} \mathrm{L}^{-1} \mathrm{~h}^{-1}\right)$ and fast in last $24 \mathrm{~h}\left(1.11 \mathrm{mg} \mathrm{L}^{-1} \mathrm{~h}^{-1}\right)$. This indicated that the expression level of HPO and AtCPR were improved by using the constitutive promoters, not the inducible promoters adopted in PK2-24. The total amount of terpenoids was up to $157.8 \pm 6.4 \mathrm{mg} \mathrm{L}^{-1}$ cell culture, which was $29.6 \mathrm{mg}$ per $\mathrm{L}$ per $\mathrm{OD}_{600}$. It was much higher than that of $P$. pastoris (0.86 mg per L per $\mathrm{OD}_{600}$ ) (Table 2).

\section{Conclusions}

A (+)-valencene related sesquiterpenoids biosynthesis pathway in $S$. cerevisiae was successfully constructed and optimized. Finally we were able to increase the synthesis of $\beta$-nootkatol by 91-fold (from 3.6 to $327.9 \mathrm{mg} \mathrm{L}^{-1}$ ) and (+)-nootkatone by 62 -fold (from 0.87 to $53.7 \mathrm{mg} \mathrm{L}^{-1}$ ) through resting cell transformation. In vivo, the level of total terpenoids was improved by 56 -fold through combining the suppression of ERG9, knockout of the negative regulator $R O X 1$ and overexpression of truncated form of HMG1 gene (tHMGR) etc. The results demonstrated the important influences of key enzymes, expression cassettes, hosts and culture temperature on sesquiterpenes production in S. cerevisiae, which could also be adapted for the bioproduction of other terpenoids and chemicals.

\section{Conflicts of interest}

There are no conflicts of interest to declare.

\section{Acknowledgements}

This work was financially supported by the Natural Science Foundation of China (Grant 21878104 and 31800063, U1701243), the Science and Technology Planning Project of Guangdong Province, China (Grant 2017A010105019) and the Project on the Integration of Industry, Education, and Research of Guangzhou, China (Grant 201704020183 and 201903010086).

\section{References}

1 M. Furusawa, T. Hashimoto, Y. Noma and Y. Asakawa, Chem. Pharm. Bull., 2006, 53, 1513-1514.

2 H. G. Haring, F. Rijkens, H. Boelens and A. Van der Gen, J. Agric. Food Chem., 1972, 20, 1018-1021.

3 FEEDAP, EFSA J., 2016, 14, 4475.

4 B. C. R. Zhu, G. Henderson, A. M. Sauer, Y. Yu, W. Crowe and R. A. Laine, J. Chem. Ecol., 2003, 29, 2695-2701.

5 A. Nemmar, S. Al-Salam, S. Beegam, P. Yuvaraju, N. Hamadi and B. H. Ali, Nutrients, 2018, 10, 263.
6 S. L. Yanran Li, K. Thodey, I. Trenchard, A. Cravens and C. D. Smolke, Proc. Natl. Acad. Sci. U. S. A., 2018, 115, 3922-3931.

7 B. Hong, R. Lebeuf, S. Delbaere, P. Alsters and V. NardelloRataj, Catalysts, 2016, 6, 184-195.

8 D. M. Palmerín-Carreño, O. M. Rutiaga-Quiñones, J. R. Verde Calvo, A. Prado-Barragán and S. Huerta-Ochoa, LWT-Food Sci. Technol., 2015, 64, 788-793.

9 T.-D. Nguyen, G. MacNevin and D.-K. Ro, De novo synthesis of high-value plant sesquiterpenoids in yeast, in Methods in enzymology, ed. D. A. Hopwood, Academic Press, 2012, vol. 517, pp. 261-278.

10 J. Lian, S. Mishra and H. Zhao, Metab. Eng., 2018, 50, 85-108. 11 C. M. Humphreys and N. P. Minton, Curr. Opin. Biotechnol., 2018, 50, 174-181.

12 A. Krivoruchko and J. Nielsen, Curr. Opin. Biotechnol., 2015, 35, 7-15.

13 Y. Zhang, J. Nielsen and Z. Liu, FEMS Yeast Res., 2017, 17, fox080.

14 S. Ostergaard, L. Olsson and J. Nielsen, Microbiol. Mol. Biol. Rev., 2000, 64, 34-50.

15 Q. Yan and S. S. Fong, Curr. Opin. Biotechnol., 2018, 53, 254263.

16 E. M. Paradise, J. Kirby, R. Chan and J. D. Keasling, Biotechnol. Bioeng., 2008, 100, 371-378.

17 J. Hong, S. H. Park, S. Kim, S. W. Kim and J. S. Hahn, Appl. Microbiol. Biotechnol., 2019, 103, 211-223.

18 J. M. Otero, W. Vongsangnak, M. A. Asadollahi, R. OlivaresHernandes, J. Maury, L. Farinelli, L. Barlocher, M. Osterås, M. Schalk, A. Clark and J. Nielsen, BMC Genomics, 2010, 11, 723.

19 A. Matthew, R. B. Kennedy and M. Bard, Biochim. Biophys. Acta, 1999, 1445, 110-122.

20 K. W. N. Henry, J. T. Edlind and D. Thomas, Eukaryotic Cell, 2002, 1, 1041-1044.

21 D. C. Amberg, D. J. Burke, D. Burke and J. N. Strathern, Methods in yeast genetics: a cold spring harbor laboratory course manual, Cold Spring Harbor Laboratory Press, 2005.

22 W. Xie, L. Ye, X. Lv, H. Xu and H. Yu, Metab. Eng., 2015, 28, 818.

23 R. P. Shetty, D. Endy and T. F. Knight Jr, J. Biol. Eng., 2008, 2, 5.

24 L. Zelcbuch, N. Antonovsky, A. Bar-Even, A. Levin-Karp, U. Barenholz, M. Dayagi, W. Liebermeister, A. Flamholz, E. Noor, S. Amram, A. Brandis, T. Bareia, I. Yofe, H. Jubran and R. Milo, Nucleic Acids Res., 2013, 41, e98.

25 J. DiCarlo, J. Norville, P. Mali, X. Rios, J. Aach and G. Church, Nucleic Acids Res., 2013, 41, 4336-4343.

26 M. Girhard, K. Machida, M. Itoh, R. Schmid, A. Arisawa and V. Urlacher, Microb. Cell Fact., 2009, 8, 36-48.

27 A. Emmerstorfer, M. Wimmer-Teubenbacher, T. Wriessnegger, E. Leitner, M. Muller, I. Kaluzna, M. Schurmann, D. Mink, G. Zellnig, H. Schwab and H. Pichler, Biotechnol. J., 2015, 10, 623-635.

28 S. Takahashi, Y.-S. Yeo, Y. Zhao, P. E. O'Maille, B. T. Greenhagen, J. P. Noel, R. M. Coates and J. Chappell, J. Biol. Chem., 2007, 282, 31744-31754. 
29 K. Cankar, A. van Houwelingen, M. Goedbloed, R. Renirie, R. M. de Jong, H. Bouwmeester, D. Bosch, T. Sonke and J. Beekwilder, FEBS Lett., 2014, 588, 1001-1007.

30 T. Wriessnegger, P. Augustin, M. Engleder, E. Leitner, M. Müller, I. Kaluzna, M. Schürmann, D. Mink, G. Zellnig, H. Schwab and H. Pichler, Metab. Eng., 2014, 24, 18-29.

31 K. van Eunen and B. M. Bakker, Perspectives in Science, 2014, 1, 126-130.

32 O. De Smidt, J. du Preez and J. Albertyn, FEMS Yeast Res., 2008, 8, 967-978.

33 O. De Smidt, J. du Preez and J. Albertyn, FEMS Yeast Res., 2012, 12, 33-47.

34 B. M. Bakker, C. Bro, P. Kötter, M. A. Luttik, J. P. van Dijken and J. T. Pronk, J. Bacteriol., 2000, 182, 4730-4737.

35 C. N. Marjohn, S. Jae-Young, N. Franz Marielle, K. Me-Sun, J. Yu Jin, K. Kwon-Kyoo, N. Illsup and C. Yong-Gu, J. Plant Biotechnol., 2016, 43, 422-431.

36 C. L. Young, D. L. Raden and A. S. Robinson, Traffic, 2013, 14, 365-381.

37 J. Beekwilder, A. van Houwelingen, K. Cankar, A. D. van Dijk, R. M. de Jong, G. Stoopen, H. Bouwmeester, J. Achkar, T. Sonke and D. Bosch, Plant Biotechnol. J., 2014, 12, 174182.

38 P. Urban, C. Mignotte, M. Kazmaier, F. Delorme and D. Pompon, J. Biol. Chem., 1997, 272, 19176-19186.

39 M. A. Asadollahi, J. Maury, M. Schalk, A. Clark and J. Nielsen, Biotechnol. Bioeng., 2010, 106, 86-96.
40 M. Z. Ding, H. F. Yan, L. F. Li, F. Zhai, L. Q. Shang, Z. Yin and Y. J. Yuan, PLoS One, 2014, 9, e109348.

41 Q. Li, Z. Sun, J. Li and Y. Zhang, FEMS Microbiol. Lett., 2013, 345, 94-101.

42 C. Gavira, R. Hofer, A. Lesot, F. Lambert, J. Zucca and D. Werck-Reichhart, Metab. Eng., 2013, 18, 25-35.

43 L. Xiong, Y. Zeng, R.-Q. Tang, H. S. Alper, F.-W. Bai and X.-Q. Zhao, Microb. Cell Fact., 2018, 17, 58.

44 S. Partow, V. Siewers, S. Bjørn, J. Nielsen and J. Maury, Yeast, 2010, 27, 955-964.

45 T. C. Williams, L. K. Nielsen and C. E. Vickers, ACS Synth. Biol., 2013, 2, 136-149.

46 N. Guaragnella, M. Zdralevic, P. Lattanzio, D. Marzulli, T. Pracheil, Z. Liu, S. Passarella, E. Marra and S. Giannattasio, Biochimica et Biophysica Acta, 2013, 1833, 2765-2774.

47 R. Nelson David, Philos. Trans. R. Soc., B, 2013, 368, 201204201230.

48 K. Cankar, A. v. Houwelingen, D. Bosch, T. Sonke, H. Bouwmeester and J. Beekwilder, FEBS Lett., 2011, 585, 178-182.

49 T. Wriessnegger, S. Moser, A. Emmerstorfer-Augustin, E. Leitner, M. Muller, I. Kaluzna, M. Schurmann, D. Mink and H. Pichler, Fungal Genet. Biol., 2016, 89, 114-125.

50 X. Guo, J. Sun, D. Li and W. Lu, Biochem. Eng. J., 2018, 137, 125-131. 